\title{
Image Data Compression Using a New Floating-Point Digital Signal Processor
}

\author{
Edward L. Siegel, Arch W. Templeton, Kenneth L. Hensley, Michael A. McFadden, Kirkman G. Baxter, \\ Mark D. Murphey, Paul E. Cronin, Ronald G. Gesell, and Samuel J. Dwyer, III
}

\begin{abstract}
A new dual-ported, floating-point, digital signal processor has been evaluated for compressing 512 and 1,024 digital radiographic images using a full-frame, twodimensional, discrete cosine transform (2D-DCT). The floating point digital signal processor operates at $\mathbf{4 9 . 5}$ million floating point instructions per second (MFLOPS). The level of compression can be changed by varying four parameters in the lossy compression algorithm. Throughput times were measured for both 2D-DCT compression and decompression. For a $1,024 \times 1,024 \times 10$-bit image with a compression ratio of $316: 1$, the throughput was 75.73 seconds (compression plus decompression throughput). For a digital fluorography 1,024 $\times 1,024 \times 8$-bit image and a compression ratio of $26: 1$, the total throughput time was 63.23 seconds. For a computed tomography image of $512 \times 512 \times 12$ bits and a compression ratio of 10:1 the throughput time was 19.65 seconds.

Copyright $\odot 1991$ by W.B. Saunders Company
\end{abstract}

KEY WORDS: image compression, discrete cosine transform, digital signal processing

$\mathbf{M}$ ODERN radiology departments generate a large number of digitally formatted radiographic images. Efficient electronic management of this huge volume of image data is constrained by large storage requirements and significant time necessary for data transmission. Data compression ${ }^{1}$ represents one way to reduce these two constrictions. The efficiency of a compression method is measured by its compression ratio. A compression ratio is defined as the number of bits in the original image compared to the number of bits in the compressed image. A compression ratio of 5:1 applied to a 1,024 $\times$ $1,024 \times 8$-bit image means that the original image of $8,388,608$ bits $(1,048,576$ bytes) can be stored in $1,677,722$ bits (209,716 Bytes).

Reversibje compression methods are bit pre-

From the Department of Diagnostic Radiology, University of Kansas Medical Center, Kansas City, KS.

Address reprint requests to Edward L. Siegel, MD, Department of Diagnostic Radiology, University of Kansas Medical Center, 39th and Rainbow Blvd, Kansas Cin, KS 66103.

Copyright $(1991$ by W.B. Saunders Company

0897-1889/91/0403-0009\$03.00/0 serving (lossless). The reconstructed image is numerically identical to the original image on a pixel-by-pixel comparison. Lossless compression algorithms typically achieve 2.5:1 ratios. Nonreversible compression (lossy) methods are such that the reconstructed image is not numerically identical to the original image. There are always image degradations. However, nonreversible compression ratios of $8: 1$ to $12: 1$ do not result in visually detectable information loss under normal viewing conditions.

Numerous studies have been conducted using lossy compression algorithms applied to radiographic images. ${ }^{2.8}$ These algorithms all employ the two-dimensional (2D) discrete cosine transform. But implementation is variable. The original image is transformed into the Fourier space where objects are mapped by the amplitude and frequency of multiple cosine waves. Large objects are represented at lower frequencies whereas smaller objects and edges are represented at higher frequencies.

The purpose of this article is to describe a new floating-point digital signal processor and to evaluate and demonstrate the impact of 2D-discrete cosine transform (DCT) lossy compression ratios on 512 and 1,024 digital array radiographs. The full-frame $2 \mathrm{D}-\mathrm{DCT}$ is implemented by applying the transform to the entire image (Fig 1). The transform coefficients are then quantized into a number of digital levels. A
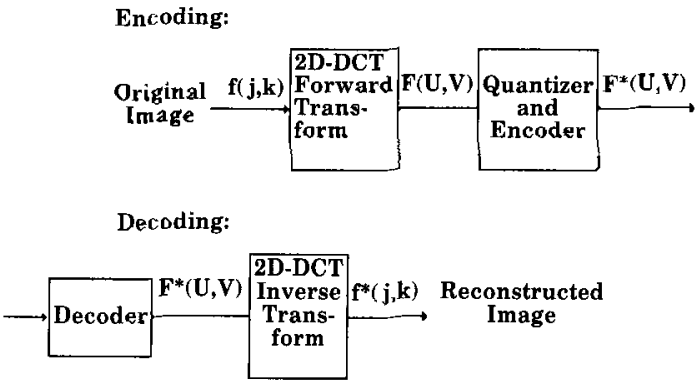

Fig 1. The 2D 2D-DCT is applied to the image. Quantization levels are implemented. The inverse 2D-DCT algorithm is applied producing the reconstructed image. 


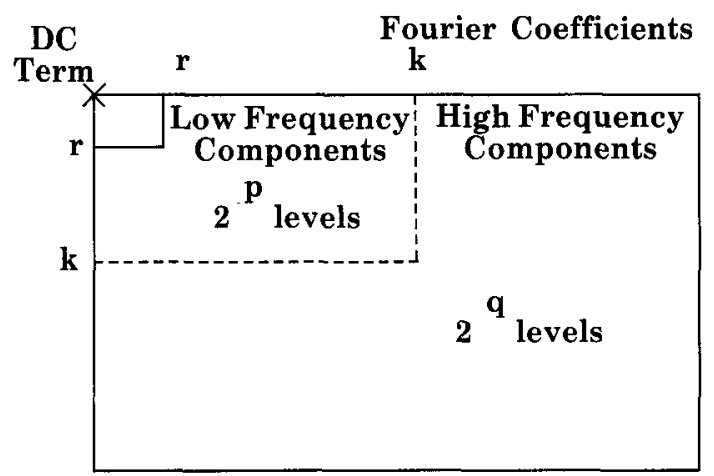

Fig 2. The 2D-DCT mapping illustrating the four parameters used for changing the compression ratios.

finer quantization (producing less distortion) may be used to represent low frequency coefficients, whereas a coarser quantization can be used for higher frequencies. A coarser quantization results in higher compression ratios but also produces more image degradation. To reconstruct an image, the inverse $2 \mathrm{D}-\mathrm{DCT}$ is applied to the quantized coefficients. The reconstructed image differs from the original image depending upon the quantization levels selected. Performing a full-frame 2D-DCT requires significant computational capacity and memory size.

It is often difficult to visually detect image degradation when 6:1 to $10: 1$ compression ratios are used. Higher compression ratios produce substantial image degradations that result in reconstructed images that are diagnostically unacceptable. A commonly used measure to quantitate the amount of difference between original and reconstructed images is to calculate the value of the root-mean-squared-error. Another method of visualizing the differences between the original image and the reconstructed image is to subtract the two and multiply the difference by a factor of 8 . An often neglected measure of compression performance is throughput times, the total time required for encoding and reconstructing the image.

\section{MATERIALS AND METHODS}

A prototype single board (Adaptive Application Accelerator, AAA, System Design Technologies, Inc, Irvine, CA) with a parallel pipeline digital signal processor (DSP) chip (96002, Motorola, Phoenix, AZ) has been used to study 2D-DCT compression of 512 and 1,024 digital arrays. The board contains two Direct Memory Access (DMA) controllers, each of which can transfer data at $66 \mathrm{Mbytes} / \mathrm{s}$ to or from any combination of memory modules to any of the external interfaces. The 96002 chip has a dual-port floating point programmable CMOS processor. The main characteristic of this DSP chip is support of the Institute of Electrical and Electronic Engineers 745 floating point standard. This standard requires single precision 8-bit exponent and 24-bit mantissa and single extended precision 11-bit exponent and 32-bit mantissa floating-point. The chip can also use 32-bit signed and unsigned fixed point arithmetic functions. It contains two identical external memory expansion ports. The DSP 96002 operates at 16.5 million instructions per second (Mips) and 49.5 million floating point instructions (MFLOPS) with a $33 \mathrm{MHz}$ clock.

The memory subsystem of the board consists of two memory modules. One module is a high-speed zero-wait static memory that contains program and coefficient storage. Standard word size is $8 \mathrm{k}$ with each word being 32 bits ( $32 \mathrm{k}$ bytes). This module can be expanded to $32 \mathrm{k}$ words

Table 1. Compression Results for a 1,024 × 1,024 $\times$ 10-Bit Image*

\begin{tabular}{|c|c|c|c|c|c|c|c|c|}
\hline \multirow[b]{2}{*}{$\mathbf{p}$} & \multirow[b]{2}{*}{$\mathrm{q}$} & \multirow[b]{2}{*}{$\begin{array}{c}\text { Compression } \\
\text { Ratio }\end{array}$} & \multicolumn{3}{|c|}{ Compression Throughput } & \multicolumn{3}{|c|}{ Decompression Throughput } \\
\hline & & & $\begin{array}{c}\text { Transfer Time } \\
\text { from Network } \\
\text { Disk to Board } \\
\text { (s) }\end{array}$ & $\begin{array}{c}\text { Compression } \\
\text { Time } \\
\text { (s) }\end{array}$ & $\begin{array}{l}\text { Transfer Time } \\
\text { from Board to } \\
\text { Network Disk } \\
\text { (s) }\end{array}$ & $\begin{array}{c}\text { Transfer Time } \\
\text { from Network } \\
\text { Disk to Board } \\
\text { (s) }\end{array}$ & $\begin{array}{c}\text { Decompression } \\
\text { Time } \\
\text { (s) }\end{array}$ & $\begin{array}{c}\text { Transfer Time } \\
\text { from Board to } \\
\text { Network Disk } \\
\text { (s) }\end{array}$ \\
\hline 5 & 4 & $316: 1$ & 14.94 & 26.03 & 0.00 & 0.05 & 25.87 & 8.84 \\
\hline 6 & 5 & $236: 1$ & 20.49 & 26.15 & 0.00 & 0.06 & 25.92 & 8.63 \\
\hline 7 & 6 & $153: 1$ & 15.60 & 26.31 & 0.05 & 0.11 & 26.09 & 8.57 \\
\hline 8 & 7 & $91: 1$ & 16.15 & 26.70 & 0.06 & 0.11 & 26.36 & 8.62 \\
\hline 9 & 8 & $47: 1$ & 17.96 & 27.41 & 0.17 & 0.21 & 26.97 & 8.63 \\
\hline 10 & 9 & $25: 1$ & 16.09 & 28.62 & 0.33 & 0.33 & 28.12 & 8.84 \\
\hline 11 & 10 & $12: 1$ & 17.25 & 31.03 & 0.77 & 0.61 & 30.81 & 8.62 \\
\hline 12 & 11 & $6: 1$ & 18.07 & 37.46 & 1.27 & 1.10 & 35.43 & 8.89 \\
\hline 13 & 12 & $4: 1$ & 16.97 & 50.15 & 1.70 & 1.60 & 39.65 & 8.68 \\
\hline 14 & 13 & $3: 1$ & 17.74 & 81.90 & 2.31 & 2.31 & 43.77 & 8.89 \\
\hline
\end{tabular}

NOTE. $r=32, k=512$.

*A storage phosphor plate $2 k \times 2 k \times 10$ bit image was averaged to $1 k \times 1 k \times 10$ bits. 
(128 k bytes). The second memory module is for data storage. The standard size is $2 \mathrm{M}$ words of 32 bits ( 8 Mbytes) but it can be expanded to $4 \mathrm{M}$ words (16 Mbytes).

The three external interfaces of the AAA board include a host interface, a general purpose port, and a multiprocessor port. The host interface is intended for the PC-AT Industry Standard Architecture (ISA) bus. This interface supports ISA 16-bit bus speeds ranging from 8 to $16 \mathrm{MHz}$ without wait states. The general purpose port provides a means of transferring data over a host's interface. The multiprocessor port allows up to four AAA boards to be interconnected for a maximum throughput of 200 MFLOPS.

In our study the AAA board was installed in a WYSE 80286 PC that is connected via Ethernet (Xerox Corp) and Novell Netware (Novell Inc, Provo, UT) to a Compaq 80386 file server (Compaq Computer Corp, Houston, TX). All disk to board transfers occurred over this network. Factors such as disk caching and file server utilization had an impact on the disk to board throughput values. However, since these throughput times were not the subject of this study, no effort was made to understand or control them. The AAA board uses Picture Image Compression Software (PICS). PICS is a library package provided for lossless and lossy image compression.

The user controls the degree of lossy compression by selecting parameters contained in the compression routines. Figure 2 illustrates the four parameters $(r, p, q$, and $k)$. The " $r$ " value determines how many coefficients adjacent to the average value (DC) term are preserved. The "p" value determines how many quantization values to use to store the low frequency components. The " $q$ " value is for quantization levels for higher frequency terms. The " $k$ " parameter determines the boundary between low and high frequency terms.

\section{RESULTS AND DISCUSSION}

The AAA board represents a new, very fast, inexpensive technology for processing 512 or

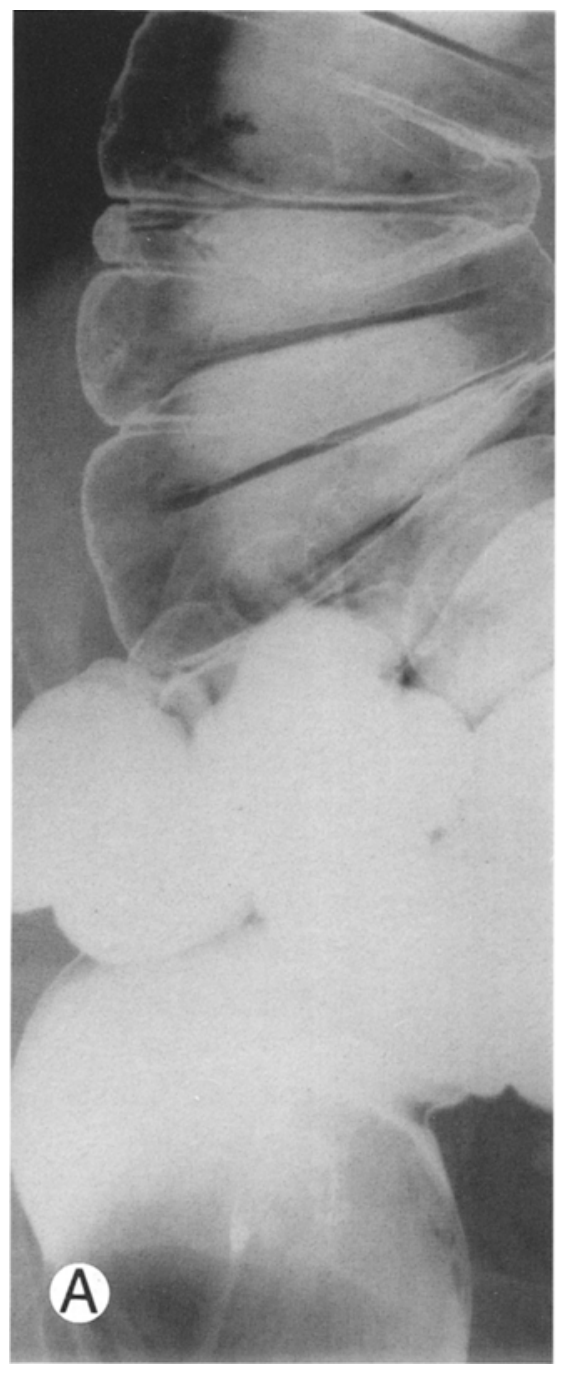

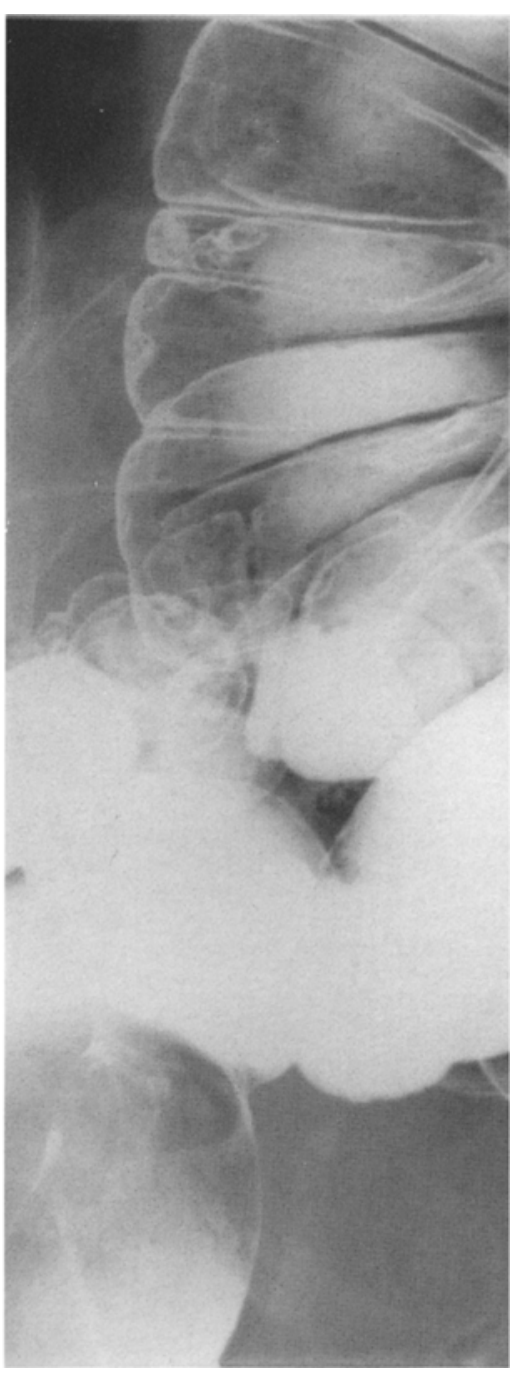

Fig 3. The original phosphor plate image averaged to $1 \mathrm{k} \times 1 \mathbf{k}$ $\times 10$ bits. An air contrast barium enema obtained using a storage phosphor plate system. 
1,024 digital arrays. A $2 \mathrm{k} \times 2 \mathrm{k} \times 10$-bit storage phosphor plate air contrast barium enema image was averaged down to $1 \mathrm{k} \times 1 \mathrm{k} \times 10$ bits and processed by the compression software on the AAA board (Table 1). Figures $3 \mathrm{~A}$ and $\mathrm{B}$ illustrate the original $1 \mathrm{k} \times 1 \mathrm{k} \times 10$-bit image and the 14:1 compression image. For large values of $p, q$ (with " $r$ " and " $k$ " fixed), the compression ratio is small but the throughput times (compression + decompression) are long. For small values of $\mathrm{p}$ and $\mathrm{q}$ (with " $\mathrm{r}$ " and " $\mathrm{k}$ " fixed), the compression ratio is large, and the throughput times are short.

A 1,024 × 1,024 × 8-bit digital fluorography image was processed by the AAA board compression software (Table 2) with parameters " $r$ " and " $k$ " fixed. Compression ratios ranged from $63: 1$ to $1.2: 1$ with, respectively, throughput times from 66.11 seconds to 140.83 seconds. Figure 4 demonstrates the original $1 \mathrm{k} \times 1 \mathrm{k} \times 8$-bit image and the 7:1 compressed image. Table 3 identifies the throughput times for fixed " $p$ " and " $q$ " parameters and varying " $k$ " and " $r$ " parameters. A $512 \times 512 \times 12$-bit computed tomography (CT) image was processed by the AAA board compression software (Table 4). The original CT image and the 10:1 compressed CT image are shown in Figs $5 \mathrm{~A}$ and $\mathrm{B}$.

The computational requirements of fullframe 2D-DCT are large compared to the block mode. The block mode entails subdividing the original $\mathrm{N} \times \mathrm{N}$ image data into smaller $\mathrm{n} \times \mathrm{n}$
Fig 3. (Cont'd). (B) The reconstructed $1 k \times 1 k \times 10$ bit phosphor plate with a 14:1 compression.
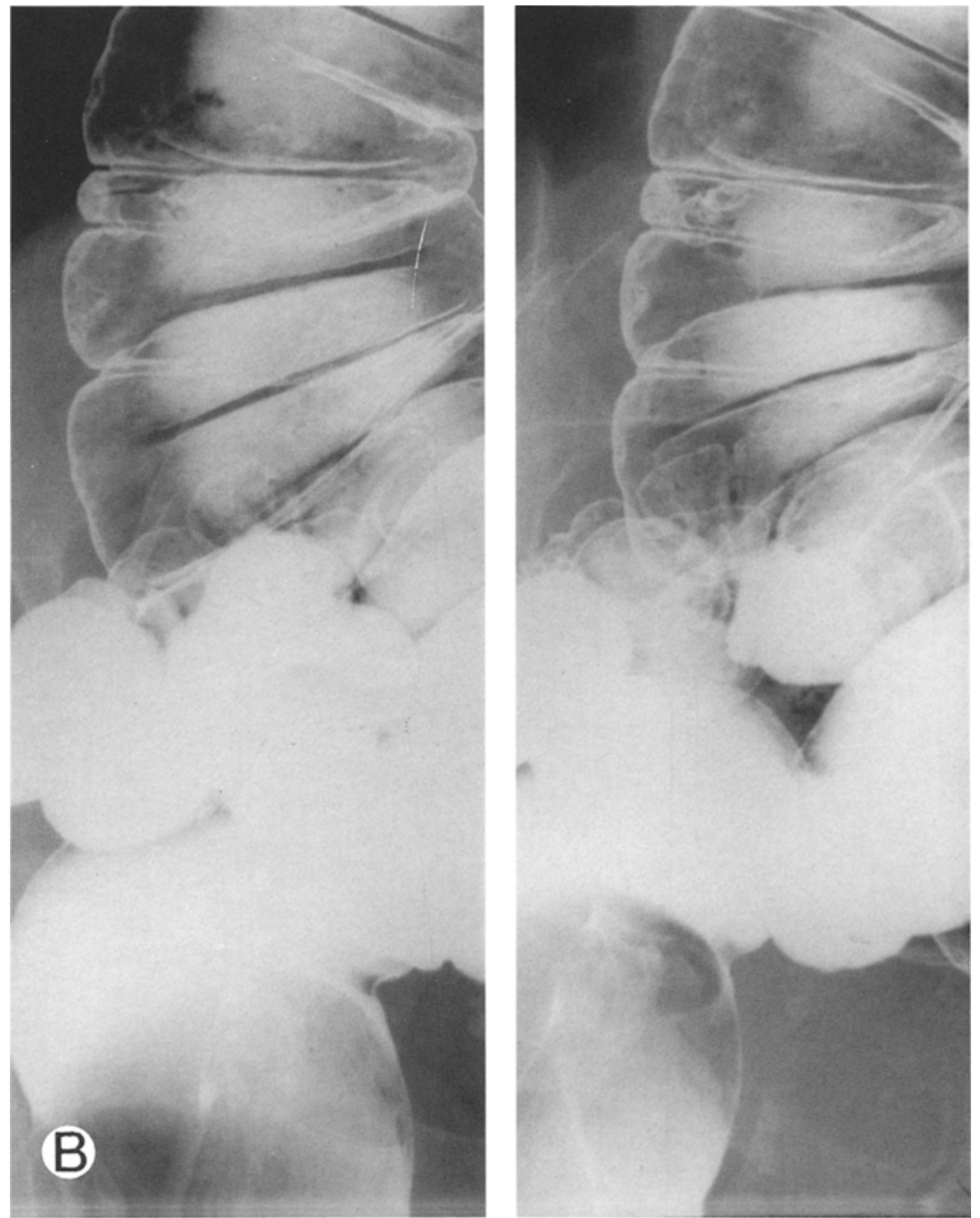
Table 2. Compression Results for a 1,024 × 1,024 × 8-Bit Image*

\begin{tabular}{|c|c|c|c|c|c|c|c|c|}
\hline \multirow[b]{2}{*}{$\mathrm{p}$} & \multirow[b]{2}{*}{$\mathbf{q}$} & \multirow[b]{2}{*}{$\begin{array}{c}\text { Compression } \\
\text { Ratio }\end{array}$} & \multicolumn{3}{|c|}{ Compression Throughput } & \multicolumn{3}{|c|}{ Decompression Throughput } \\
\hline & & & $\begin{array}{c}\text { Transfer Time } \\
\text { from Network } \\
\text { Disk to Board } \\
\text { (s) }\end{array}$ & $\begin{array}{l}\text { Compression } \\
\text { Time } \\
\text { (s) }\end{array}$ & $\begin{array}{l}\text { Transfer Time } \\
\text { from Board to } \\
\text { Network Disk } \\
\text { (s) }\end{array}$ & $\begin{array}{c}\text { Transfer Time } \\
\text { from Network } \\
\text { Disk to Board } \\
\text { (s) }\end{array}$ & $\begin{array}{l}\text { Decompression } \\
\text { Time } \\
\text { (s) }\end{array}$ & $\begin{array}{c}\text { Transfer Time } \\
\text { from Board to } \\
\text { Network Disk } \\
\text { (s) }\end{array}$ \\
\hline 5 & 4 & $63: 1$ & 8.62 & 26.47 & 0.06 & 0.05 & 26.14 & 4.77 \\
\hline 6 & 5 & $26: 1$ & 4.56 & 27.02 & 0.17 & 0.11 & 26.86 & 4.51 \\
\hline 7 & 6 & $13: 1$ & 4.72 & 28.13 & 0.28 & 0.39 & 28.18 & 4.45 \\
\hline 8 & 7 & $7: 1$ & 4.61 & 29.66 & 0.55 & 0.55 & 30.37 & 4.45 \\
\hline 9 & 8 & $4: 1$ & 4.78 & 31.85 & 0.99 & 0.88 & 33.56 & 4.78 \\
\hline 10 & 9 & $3: 1$ & 10.00 & 34.82 & 1.54 & 1.38 & 37.40 & 4.83 \\
\hline 11 & 10 & $2: 1$ & 10.38 & 39.21 & 2.69 & 2.64 & 41.57 & 4.39 \\
\hline 12 & 11 & $1.5: 1$ & 11.04 & 47.78 & 2.80 & 2.69 & 45.48 & 4.78 \\
\hline 13 & 12 & $1.2: 1$ & 10.28 & 69.64 & 3.52 & 3.57 & 49.10 & 4.72 \\
\hline 14 & 13 & $1: 1$ & 10.05 & 133.53 & 4.78 & 4.12 & 52.23 & 4.34 \\
\hline
\end{tabular}

NOTE. $r=32, k=512$.

${ }^{*} \mathrm{~A} 1 \mathrm{k} \times 1 \mathrm{k} \times 8$-bit digital fluorography image.

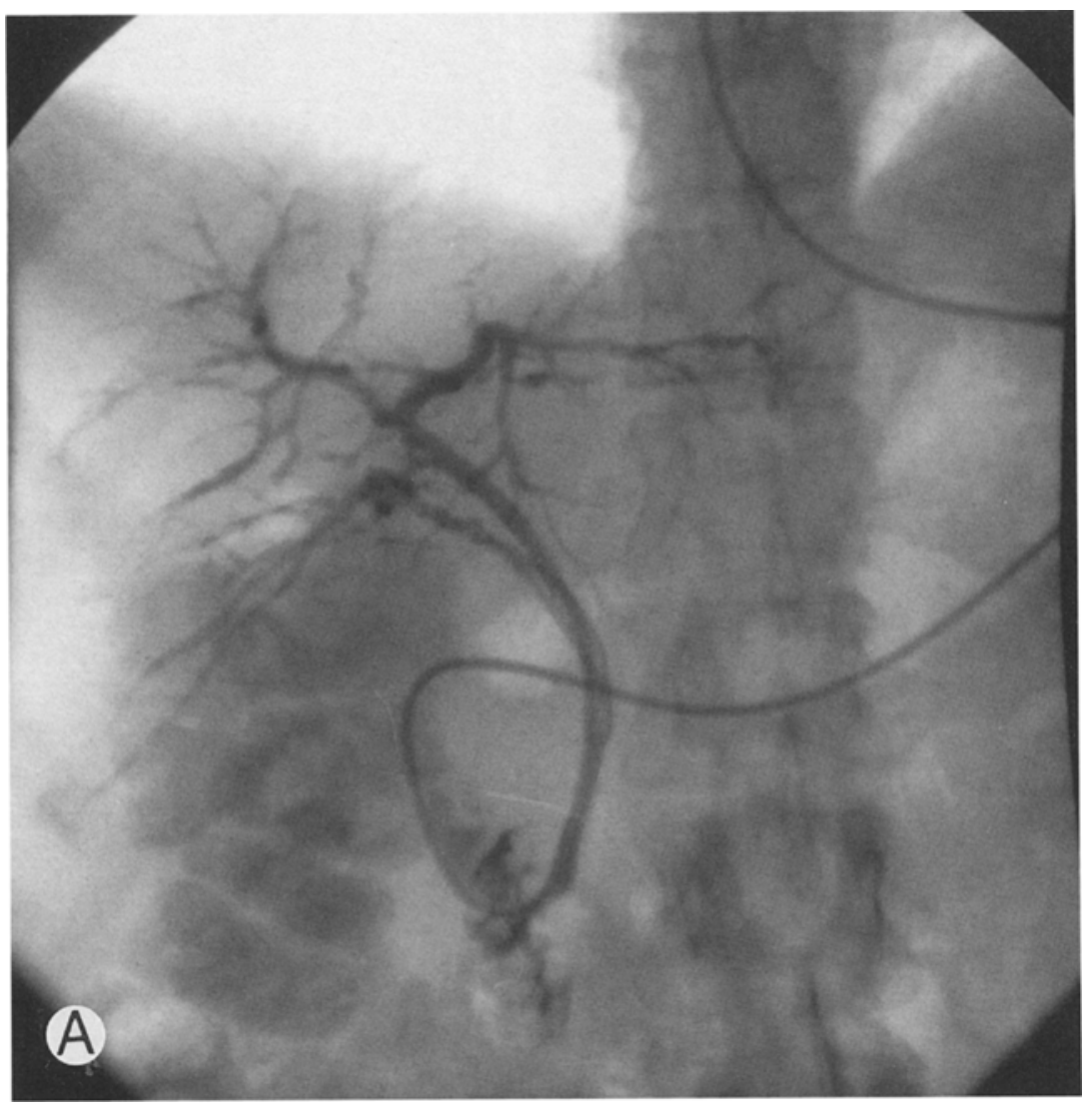

Fig 4. A retrograde cholangiogram using a digital fluorography system. (A) The original $1024 \times 1024 \times 8$ bit image. 
Table 3. Compression Results for a 1,024 × 1,024 × 8-Bit Image*

\begin{tabular}{|c|c|c|c|c|c|c|c|c|}
\hline \multirow[b]{2}{*}{$k$} & \multirow[b]{2}{*}{$r$} & \multirow[b]{2}{*}{$\begin{array}{c}\text { Compression } \\
\text { Ratio }\end{array}$} & \multicolumn{3}{|c|}{ Compression Throughput } & \multicolumn{3}{|c|}{ Decompression Throughput } \\
\hline & & & $\begin{array}{c}\text { Transfer Time } \\
\text { from Network } \\
\text { Disk to Board } \\
\text { (s) }\end{array}$ & $\begin{array}{l}\text { Compression } \\
\text { Time } \\
\text { (s) }\end{array}$ & $\begin{array}{l}\text { Transfer Time } \\
\text { from Board to } \\
\text { Network Disk } \\
\text { (s) }\end{array}$ & $\begin{array}{l}\text { Transfer Time } \\
\text { from Network } \\
\text { Disk to Board } \\
\text { (s) }\end{array}$ & $\begin{array}{c}\text { Decompression } \\
\text { Time } \\
\text { (s) }\end{array}$ & $\begin{array}{c}\text { Transfer Time } \\
\text { from Board to } \\
\text { Network Disk } \\
\text { (s) }\end{array}$ \\
\hline 128 & 32 & $9: 1$ & 8.24 & 28.61 & 0.44 & 0.44 & 29.28 & 5.05 \\
\hline 256 & 32 & $8: 1$ & 12.36 & 28.78 & 0.44 & 0.43 & 29.55 & 4.40 \\
\hline 384 & 32 & $7: 1$ & 11.86 & 29.17 & 0.49 & 0.49 & 29.88 & 4.89 \\
\hline 512 & 32 & $7: 1$ & 4.34 & 29.66 & 0.60 & 0.55 & 30.37 & 4.28 \\
\hline 640 & 32 & $6: 1$ & 4.62 & 30.26 & 0.61 & 0.60 & 30.98 & 4.84 \\
\hline 768 & 32 & $5: 1$ & 4.28 & 30.76 & 0.71 & 0.71 & 31.70 & 4.40 \\
\hline 512 & 4 & $123: 1$ & 4.34 & 26.42 & 0.06 & 0.06 & 26.03 & 5.05 \\
\hline 512 & 8 & $30: 1$ & 4.39 & 27.14 & 0.11 & 0.17 & 26.80 & 4.39 \\
\hline 512 & 12 & $21: 1$ & 4.34 & 27.35 & 0.22 & 0.16 & 27.30 & 4.33 \\
\hline 512 & 16 & $14: 1$ & 4.40 & 28.07 & 0.28 & 0.33 & 28.12 & 4.39 \\
\hline
\end{tabular}

NOTE. $p=8, q=7$

${ }^{*} \mathrm{~A} 1 \mathrm{k} \times 1 \mathrm{k} \times 8$-bit digital fluorography image.

Fig 4. (Cont'd). (B) A reconstructed image following a 7:1 compression.

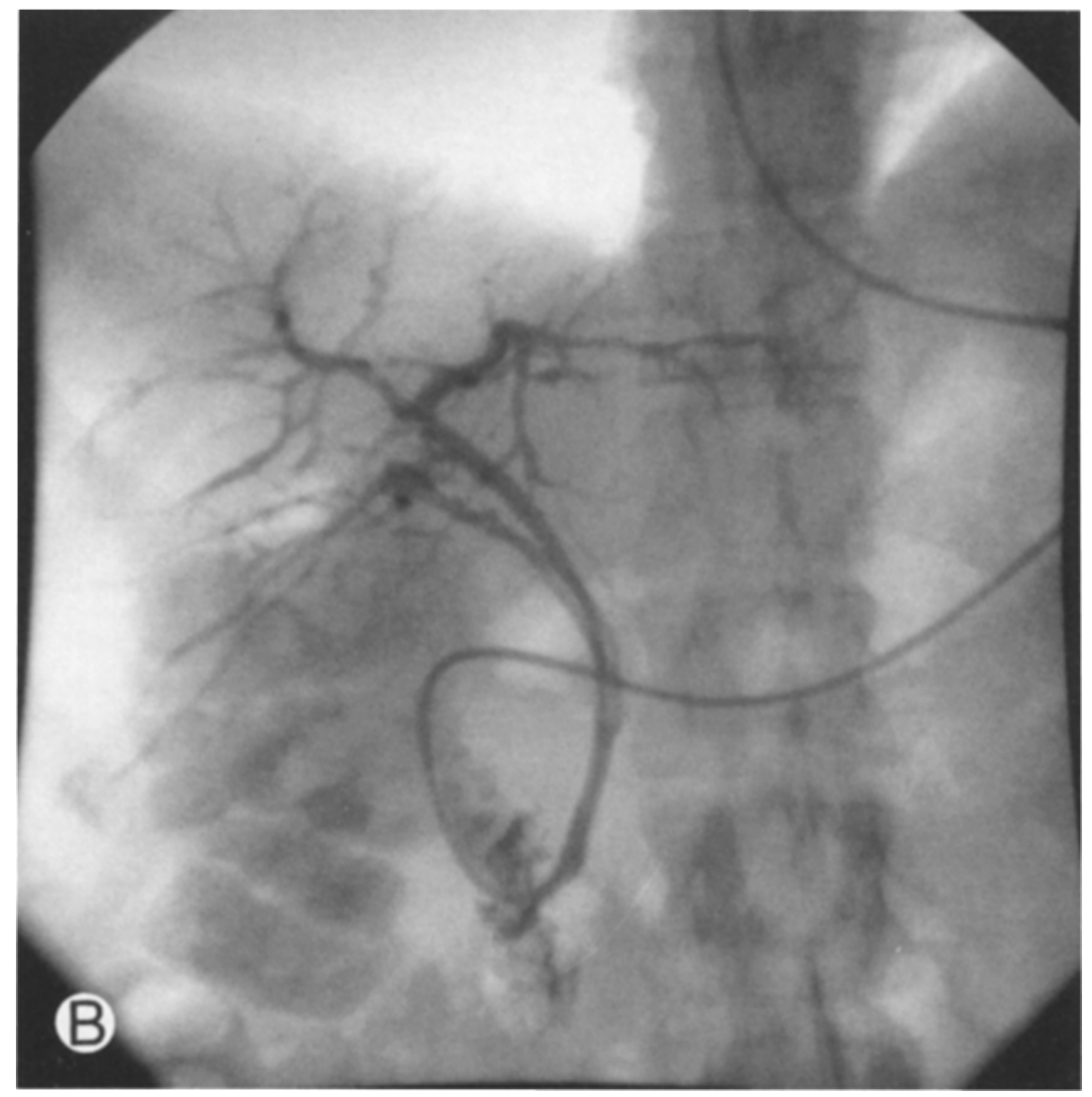




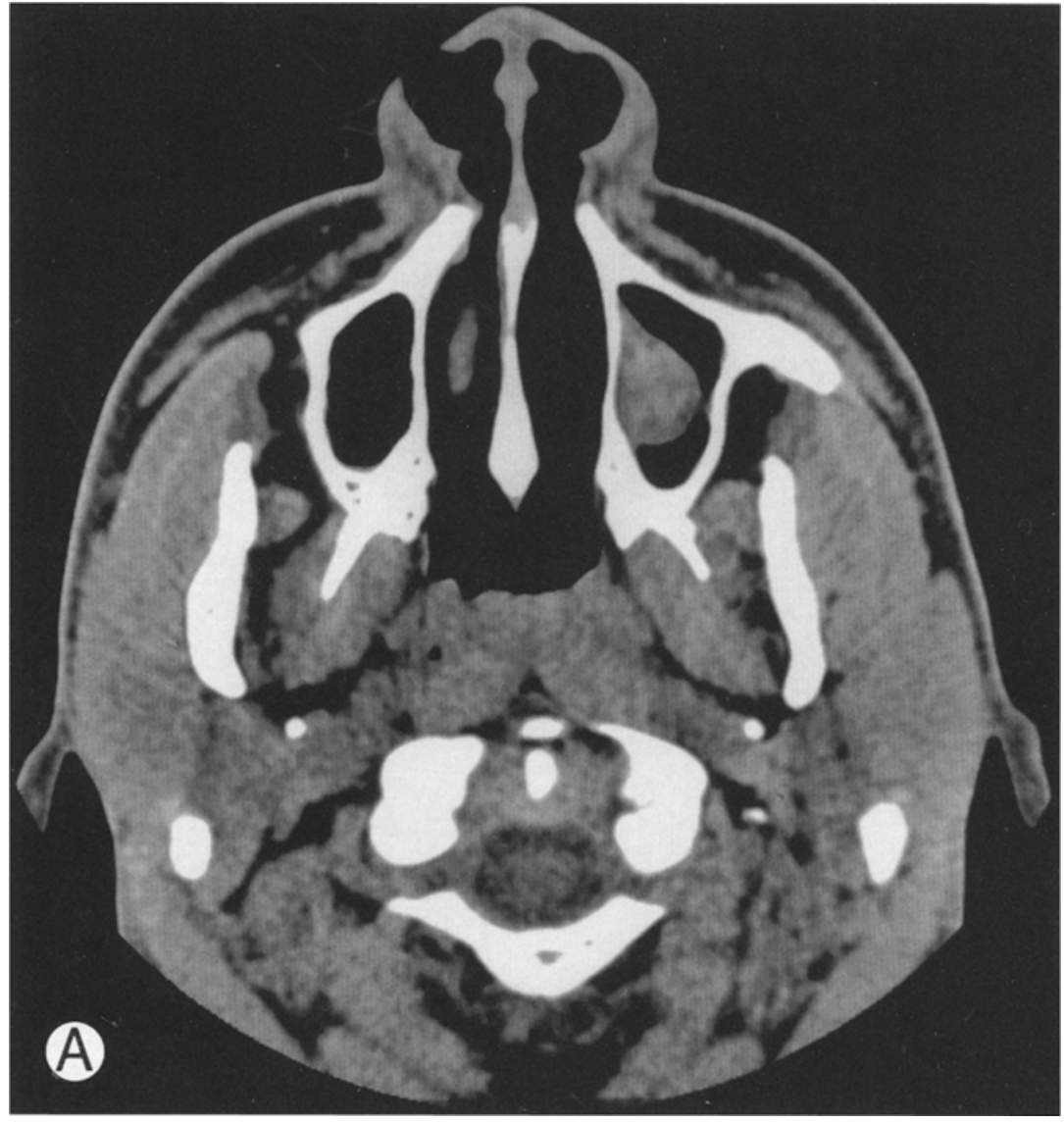

Fig 5. A cranial CT image. (A) The original $512 \times 512 \times 12$ bit image.

Table 4. Compression Results for a $512 \times 512 \times 12$-Bit Image*

\begin{tabular}{|c|c|c|c|c|c|c|c|c|}
\hline \multirow[b]{2}{*}{$\mathrm{p}$} & \multirow[b]{2}{*}{$q$} & \multirow[b]{2}{*}{$\begin{array}{l}\text { Compression } \\
\text { Ratio }\end{array}$} & \multicolumn{3}{|c|}{ Compression Throughput } & \multicolumn{3}{|c|}{ Decompression Throughput } \\
\hline & & & $\begin{array}{c}\text { Transfer Time } \\
\text { from Network } \\
\text { Disk to Board } \\
\text { (s) }\end{array}$ & $\begin{array}{l}\text { Compression } \\
\text { Time } \\
\text { (s) }\end{array}$ & $\begin{array}{c}\text { Transfer Time } \\
\text { from Board to } \\
\text { Network Disk } \\
\text { (s) }\end{array}$ & $\begin{array}{c}\text { Transfer Time } \\
\text { from Network } \\
\text { Disk to Board } \\
\text { (s) }\end{array}$ & $\begin{array}{l}\text { Decompression } \\
\text { Time } \\
\text { (s) }\end{array}$ & $\begin{array}{c}\text { Transfer Time } \\
\text { from Board to } \\
\text { Network Disk } \\
\text { (s) }\end{array}$ \\
\hline 5 & 4 & $117: 1$ & 3.68 & 6.28 & 0.00 & 0.05 & 6.10 & 2.09 \\
\hline 6 & 5 & $76: 1$ & 1.98 & 6.32 & 0.05 & 0.05 & 6.21 & 2.15 \\
\hline 7 & 6 & $48: 1$ & 2.08 & 6.43 & 0.06 & 0.06 & 6.32 & 2.03 \\
\hline 8 & 7 & $29: 1$ & 2.03 & 6.65 & 0.05 & 0.06 & 6.53 & 2.09 \\
\hline 9 & 8 & $19: 1$ & 1.98 & 7.09 & 0.11 & 0.11 & 6.75 & 2.09 \\
\hline 10 & 9 & $10: 1$ & 1.98 & 7.91 & 0.16 & 0.16 & 7.30 & 2.14 \\
\hline 11 & 10 & $7: 1$ & 1.98 & 10.05 & 0.27 & 0.28 & 8.13 & 2.36 \\
\hline 12 & 11 & $5: 1$ & 2.63 & 15.49 & 0.39 & 0.38 & 8.79 & 2.14 \\
\hline 13 & 12 & $4: 1$ & 2.31 & 31.20 & 0.49 & 0.55 & 9.56 & 2.25 \\
\hline 14 & 13 & $3: 1$ & 2.14 & 76.12 & 0.66 & 0.66 & 10.43 & 2.64 \\
\hline
\end{tabular}

NOTE. $r=16, k=256$.

*ACT image. 
Fig 5. (Cont'd). (B) The reconstructed image following 10:1 compression.

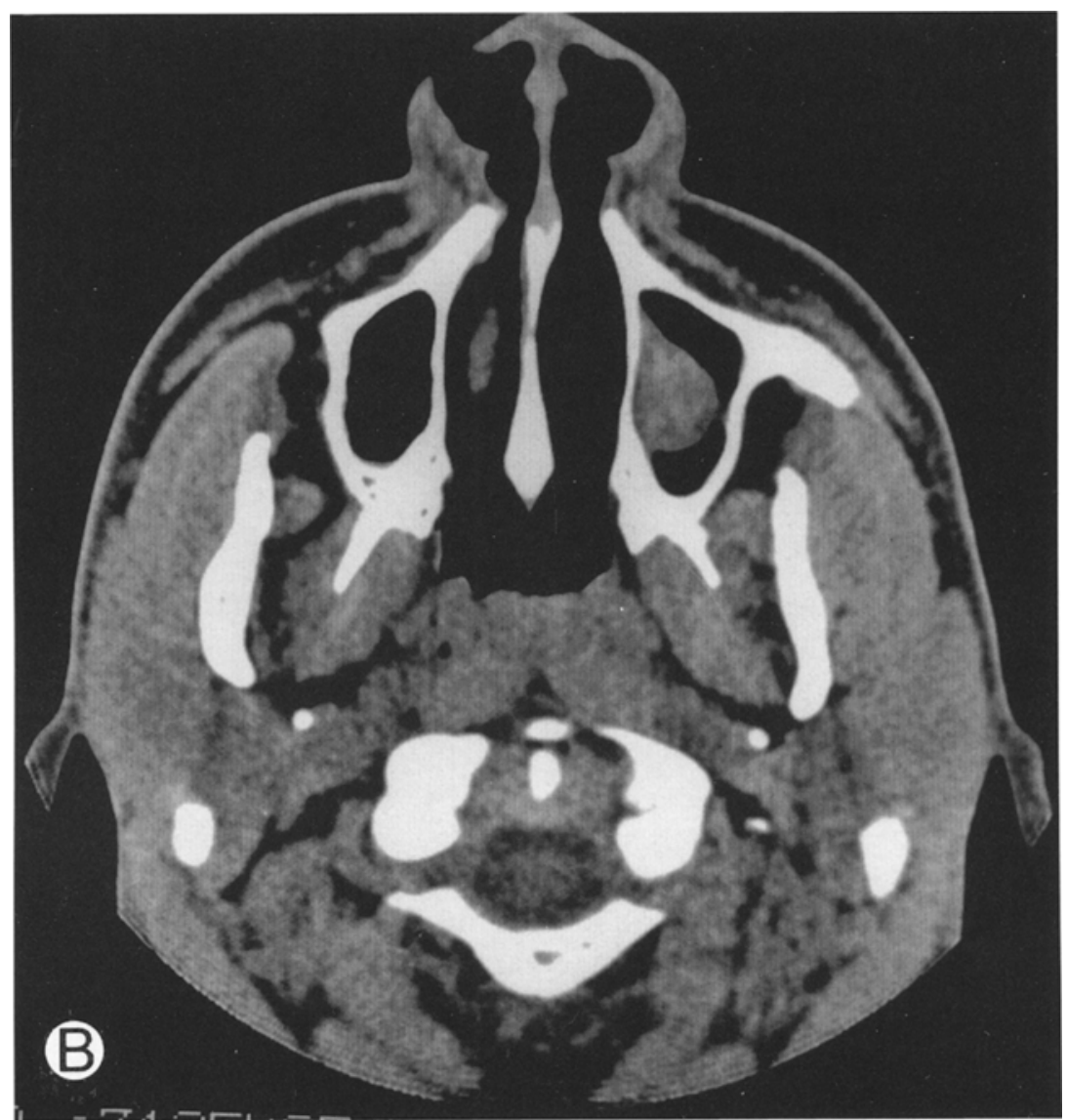

( $\mathrm{n}=8$ or 16 ) blocks and then performing a 2D-DCT on each block. The processing load to perform a full-frame 2D-DCT compared to the block mode on a $1 \mathrm{k} \times 1 \mathrm{k}$ image is about 100 to 1. The compression and decompression compu- tation times listed in Tables 1 through 4 are for a prototype AAA board. It is estimated that these times can be reduced by a factor of 2 with a faster clock and a faster memory to be installed in several months.

\section{REFERENCES}

1. Lynch TJ: Data Compression: Techniques and Applications. Lifetime Learning Publications, Belmont, CA, 1985

2. Lo SH, Huang HK: Radiological image compression: Full-frame bit-allocation technique. Radiol 155:811-817, 1985

3. Lo SH, Huang HK: Compression of radiological images with 512, 1,024, and 2,048 matrices. Radiol 161:519525,1986

4. Bramble JM, Cook LT, Murphey MD, et al: Image data compression in magnification hand radiography. $\mathrm{Ra}$ diol 170:133-136, 1989

5. Bramble JM: Comparison of information-preserving and information-losing data-compression algorithms for CT images. Radiol 170:453-455, 1989

6. Chan HK, Lou SL, Huang HK: Full-frame transform compression of CT and MR images. Radiol 171:847-851, 1989

7. Ishigaki $T$, Sakuma $S$, Ikeda $M$, et al: Clinical evaluation of irreversible image compression: Analysis of chest imaging with computed radiography. Radiol 175:739-743, 1990

8. MacMahon H, Doi K, Sanada S, et al: Data compression: Effect on diagnostic accuracy in digital chest radiography. Radiol 178:175-179, 1991 